\title{
No effect of probiotics on respiratory allergies: a seven-year follow-up of a randomized controlled trial in infancy
}

Thomas Abrahamsson, Ted Jakobsson, Bengt Björksten, Göran Oldaeus and Maria Jenmalm

\section{Linköping University Post Print}

\section{Tweet}

N.B.: When citing this work, cite the original article.

This is the pre-reviewed version of the following article:

Thomas Abrahamsson, Ted Jakobsson, Bengt Björksten, Göran Oldaeus and Maria Jenmalm, No effect of probiotics on respiratory allergies: a seven-year follow-up of a randomized controlled trial in infancy, 2013, Pediatric Allergy and Immunology, (24), 6, 556-561.

which has been published in final form at:

http://dx.doi.org/10.1111/pai.12104

Copyright: Wiley-Blackwell

http://eu.wiley.com/WileyCDA/Brand/id-35.html

Postprint available at: Linköping University Electronic Press

http://urn.kb.se/resolve?urn=urn:nbn:se:liu:diva-97655 
No effect of probiotics on respiratory allergies: a seven-year follow up of a randomised controlled trial in infancy

\author{
Thomas R Abrahamsson, $\mathrm{MD}, \mathbf{P h D}^{1}$ \\ Ted Jakobsson, $\mathrm{MD}^{1}$ \\ Bengt Björkstén, $\mathrm{MD}, \mathbf{P h D}^{2}$ \\ Göran Oldaeus, $\mathbf{M D}, \mathbf{P h D}^{3}$ \\ Maria C Jenmalm, $\mathbf{P h D}^{1,4}$
}

1. Department of Clinical and Experimental Medicine, Division of Pediatrics, Linköping University, Sweden

2. Institute of Environmental Medicine, Karolinska Institutet, Stockholm, and School of Health and Medical Sciences, Örebro University, Sweden

3. Department of Pediatrics, County Hospital Ryhov, Jönköping, Sweden

4. Department of Clinical and Experimental Medicine, Unit of Autoimmunity and Immune Regulation, Division of Inflammation Medicine, Linköping University, Sweden

Running title: 7-year follow up after L. reuteri suppl.

Correspondence to: Thomas Abrahamsson

Division of Paediatrics 
Linköping University Hospital

SE-581 85 Linköping, Sweden

Phone: +46-(10)-103 0000

Fax: +46-(13)-148265.

E-mail: thomas.abrahamsson@lio.se

Word count: 2493

Number of tables: 3

Material in electronic repository: 1 table 


\title{
Abrahamsson TR, Jakobsson T, Björkstén B, Oldaeus G, Jenmalm MC. No effect of probiotics on respiratory allergies: a seven-year follow up of a randomised controlled trial in infancy. Pediatr Allergy Immunolol
}

\begin{abstract}
Background: Supplementation with the probiotic Lactobacillus reuteri reduced the incidence of IgE-associated allergic disease in infancy. This treatment might therefore also reduce the risk for asthma and allergic rhinoconjunctivitis in school age.
\end{abstract}

Objective: To evaluate whether perinatal and infant supplementation with Lactobacillus reuteri reduced the prevalence of respiratory allergic disease in school age, and to explore whether this supplementation was associated with any long-term side effects.

Methods: A randomised, placebo-controlled trial with oral supplementation with Lactobacillus reuteri ATCC $55730\left(1 \times 10^{8} \mathrm{CFU}\right)$ during the last month of gestation and through the first year of life, comprising 232 families with allergic disease, of whom 184 completed a 7-year follow up. The primary outcomes at seven years of age were allergic disease and skin prick test reactivity (ClinicalTrials.gov ID NCT01285830).

Results: The prevalence of asthma (15\% in the probiotic vs. $16 \%$ in placebo group), allergic rhinoconjunctivitis (27\% vs. 20\%), eczema (21\% vs. 19\%) and skin prick test reactivity (29\% vs. 26\%) were similar in the probiotic and placebo group. Growth indices and gastrointestinal symptoms were similar in the two groups. No severe adverse events were reported.

Conclusion: The effect of Lactobacillus reuteri on sensitisation and IgE-associated eczema in infancy did not lead to a lower prevalence of respiratory allergic disease in school age. Thus, the effect of Lactobacillus reuteri on the immune system seems to be transient. 
Administration of Lactobacillus reuteri during the last weeks of gestation and in infancy was not associated with any long-term side effects.

\section{Key words}

Randomised; probiotics; prevention; children; eczema; asthma; allergic rhinoconjunctivitis;

skin prick test; sensitisation; fractional exhaled nitric oxide

Correspondence to: Thomas Abrahamsson

Division of Paediatrics

Linköping University Hospital

SE-581 85 Linköping, Sweden

Phone: +46-(10)-103 0000

Fax: +46-(13)-148265.

E-mail: thomas.abrahamsson@lio.se 


\section{Introduction}

A deprived microbial exposure may underlie the increase of allergic diseases in affluent countries $(1,2)$. Probiotics are live micro-organisms which upon ingestion have been shown to exert health benefits in clinical studies, and it has been hypothesised that probiotics may reduce the risk for allergic disease (3). Indeed, there are several double-blind placebocontrolled studies reporting a lower incidence of eczema until two years of age after oral supplementation with probiotics during the perinatal period and infancy (3). According to the atopic march theory, eczema and food allergy are typically outgrown and replaced in school age by allergic asthma and rhinoconjuntivitis (4). Consequently, it was expected that the probiotic treated children in these trials would have less respiratory allergic disease when they reached school age. The results of the first two follow ups, however, have been discouraging $(5,6)$. Despite a much lower eczema incidence at two years of age in the Lactobacillus GG (LGG) treated infants compared to the placebo group, 23\% vs. 46\% (7), there were no effect on respiratory disease at seven years of age (5). Furthermore, LGG intake did not influence sensitization rates ate any age $(5,7)$. The asthma prevalence even tended to be higher in the LGG than the placebo group, 17\% vs. 5\%. Neither was there any effect on respiratory allergic disease in the 5-year follow up in a second prevention trial evaluating a mixture of prebiotics and five different probiotic strains (6). In a clinical trial in New Zealand, in which a L. rhamnosus strain was tested, however, although there was no effect on sensitisation at two years (8), the prevalence of rhinoconjunctivitis was lower in the probiotic than the placebo group at the 4-year follow up (9).

Possibly, the lack of effect on IgE-mediated sensitisation in infancy in these studies $(7,10)$ could provide clues to the loss of power. Although IgE-mediated sensitisation is a common feature in eczema, recent articles suggest that IgE-mediated reactions are only part of a 
much more complex immunological picture in eczema (11). The predictive value of nonIgE-associated eczema for subsequent asthma is also low. Approximately $14 \%$ of the nonsensitised infants with eczema develop asthma in school age compared with $60 \%$ of the sensitised infants with eczema (12).

In contrast to the probiotic strains in the other studies (3), Lactobacillus reuteri ATCC 55730 had an effect on sensitisation measures in infancy in a prevention study previously reported by us (13). Although a similar eczema incidence was observed in the L. reuteri and placebo group until two years of age, the prevalence of IgE-associated eczema, $8 \%$ vs, $20 \%$ (13), and the cumulative incidence of IgE-associated allergic disease, 20\% vs. 35\% (14), were lower in the $L$. reuteri than in the placebo treated infants. Also, skin prick test (SPT) reactivity was less common in the L. reuteri than in the placebo group, significantly so for infants with allergic mothers, $14 \%$ vs. $31 \%$ (13). We therefore hypothesised that the L. reuteri treated infants would run a reduced risk to develop later respiratory allergic disease. The aim of the present study was to evaluate whether perinatal and infant supplementation with L . reuteri reduced the prevalence of asthma and allergic rhinoconjunctivitis in early school age. 


\section{Methods}

\section{Study design}

This was a follow up study at seven years of infants completing a randomised double-blind placebo-controlled trial evaluating the effect of $L$. reuteri on allergic disease and sensitisation until two years of age (13). Between January 2001 and April 2003, 232 families with allergic disease (i.e. one or more family members with eczema, asthma, gastrointestinal allergy, allergic urticaria, or allergic rhinoconjunctivitis) were recruited at antenatal clinics. The pregnant mothers were randomised before gestational week 35 either to the $L$. reuteri or the placebo group. Randomisation was stratified for each study centre. Each centre was provided an allocation list with unique ID-numbers for each subject. Prior to randomisation, each study product bottle was labelled with the unique ID-number and randomly mixed by an independent contract manufacturer. The mothers started taking L. reuteri ATCC 57730 (five oil drops corresponding to 1 x $10^{8} \mathrm{CFU} /$ day, BioGaia AB, Stockholm, Sweden) or placebo from gestational week $36+0$ and continued daily until delivery. After birth, the baby continued with the same study product as its mother, daily up to 12 months of age. The recovery rate of $L$. reuteri in stool samples was high, approximately $80 \%$ among the probiotic treated infants during the supplementation period (15). Compliance with the treatment regime was never below 97\% during the first year of life, as assessed by interviews and by collecting used study product bottles at every visit, and no infants in the placebo group received probiotics (15). In total 188 infants completed the original study, 95 in the L. reuteri and 93 in the placebo group. The study was double-blind until all infants had completed the 2-year follow up. These families were subsequently contacted for a follow up at seven years of age, and 94 in in the L. reuteri and 90 in the placebo group participated. Of the non-partipicating children, one in the placebo group had IgE-associated eczema, and one in each treatment group had non-sensitised eczema at two years of age. At seven years of age, $19 \%$ in the $L$. 
reuteri and 26\% in placebo group reported to have taken probiotics (any probiotic strain) during the last month $(\mathrm{p}=0.30)$. The baseline characteristics of the participating children are displayed in Table 1. The study is registered at ClinicalTrials.gov (NCT01285830). A written informed consent was obtained from both parents before inclusion. The Regional Ethics Committee for Human Research at Linköping University approved the study (M171-07).

\section{Clinical investigations}

Follow-up was performed by research nurses at seven years of age ( \pm 3 months). Before the visit the parents completed a questionnaire based on the ISAAC questionnaire for 6-7 year old children (http://isaac.auckland.ac.nz/Index.html), supplemented with questions regarding gastrointestinal symptoms, antibiotic and probiotic intake the last months, family size, pets and parental smoking (Table 1). The visits included structured interviews related to symptoms of allergic disease, physical examination, spirometry and measurement of fractional exhaled nitric oxid $\left(\mathrm{FE}_{\mathrm{NO}}\right)$. The SCORAD index was used to assess the severity of the eczema (16). Spirometry was performed with Jaeger Masterscope version 4.5 (Erich Jaeger GmbH, Würzburg, Germany). Forced expiratory volume at 1 second $\left(\mathrm{FEV}_{1.0}\right)$, and the functional vital capacity (FVC) were assessed. The FVC\% was calculated from the ratio $\mathrm{FEV}_{1.0} / \mathrm{FVC}$. A FVC\% $<80 \%$ was regarded as pathological. Reversibility test with $\mathrm{FEV}_{1.0}$ measurement before and after inhalation of a $\beta$-agonist ( $1 \mathrm{mg}$ Terbutaline) was regarded as positive if $\mathrm{FEV}_{1.0}$ increased $\geq 12 \%$ (http://www.ginasthma.com). Only spirometry measurements with good quality, 120 out of 156 (77\%) measurements, were included in the analyses. The $\mathrm{FE}_{\mathrm{NO}}$ was measured at a constant flow of $50 \mathrm{~mL} / \mathrm{s}$ with NIOX-MINO (Aerocrine AB, Stockholm, Sweden). The cut off level for a pathological $\mathrm{FE}_{\mathrm{NO}}$ was $20 \mathrm{ppb}$, which is the $95 \%$ percentile in 7-9 year old children. (17) Skin prick tests were done on the volar aspects of the forearm with egg white, fresh skimmed cow milk (lipid concentration 0.5\%) and standardised cat, dog, 
birch, peanut, mite (Der p) and timothy extracts (Soluprick ${ }^{\circledR}$, ALK, Hørsholm, Denmark). Histamine hydrochloride (10 $\mathrm{mg} / \mathrm{ml}$ ) was used as positive and albumin diluent as negative control. The test was regarded as positive if the mean diameter of the wheal was $\geq 3 \mathrm{~mm}$.

\section{Diagnostic criteria}

The primary outcomes at seven years of age were allergic disease and skin prick test reactivity. Allergic disease included asthma, allergic rhinoconjunctivitis (ARC), allergic urticaria and eczema. The child should have had symptoms of and/or have been treated for the actual allergic disease during the last 12 months. Thus, children with allergic disease before school age that have not had any symptoms during the last 12 months were defined as healthy. Wheeze was defined as an episode with obstructive airway symptoms. Asthma diagnosis required at least one of following two criteria: 1. Doctor diagnosis and asthma symptoms and/or medication during the last 12 months; 2 . Wheeze or nocturnal cough and a positive reversibility test and/or pathological $\mathrm{FE}_{\mathrm{NO}}$ value. In Sweden most children with asthma are asymptomatic when visiting the doctor, since they are efficiently treated with inhaled corticosteroids. If the asthma diagnosis was based on doctors diagnosis, medical records of the child was always reviewed to confirm that the diagnosis were consistent with the GINA criteria (http://www.ginasthma.com). The diagnosis of ARC was based on standard ISAAC question (18) and required watery discharge at least twice in contact with the same allergen and no signs of infection. Urticaria was defined as allergic when appearing at least twice in conjunction with a certain food. Eczema was defined as a pruritic, chronic or chronically relapsing non-infectious dermatitis with typical features and distribution, as suggested by Hanifin and Rajka (19). Eczema was classified as IgE-associated if the infant had also a positive skin prick test. 


\section{Statistical analysis}

The $X^{2}$ test was used to compare the prevalence of outcome variables and background factors between the groups. Fisher's exact test was used when the expected frequency for any cell was less than five. Logistic regression was employed for adjustment for possible confounders. Continuous variables were analysed with student's t-test. As SCORAD scores and spirometry and $\mathrm{FE}_{\mathrm{NO}}$ values were not normally distributed, the groups were compared using MannWhitney $U$ test for these analyses. A probability level of $<0.05$ was considered to be statistically significant. The calculations were performed using the statistical package IBM SPSS Statistics 20 (IBM Corp, NY, USA) 


\section{Results}

The prevalence of asthma, allergic rhinoconjunctivitis, eczema and skin prick test reactivity was similar in the probiotic and placebo group (Table 2). Neither were there any significant differences in the compound variables allergic disease and respiratory allergic disease between the treatment groups. The prevalence of children with IgE-associated eczema, in this study defined as SPT positive children with eczema, was also similar. The positive predictive value of IgE-associated eczema in infancy was only 33\% for asthma and 39\% for allergic rhinoconjunctivitis at seven years of age (Supplementary Table 1).

In the original study, the effect of $L$. reuteri treatment on SPT reactivity was stronger when only infants with mother with allergic diseases were included (13). No such effect was seen at seven years of age. Thus, the prevalence of positive SPT was $18 \%$ and $20 \%$ in the L. reuteri and placebo group, respectively, after such stratification. Neither did stratification according to delivery mode, asthma heredity and probiotic intake during the last month affect the result (data not shown). Antibiotic prescription during the first year of life was more common in the L. reuteri than the placebo group (Table 1), and boys had asthma more often than girls at seven years of age, $21 \%$ (20/96) vs. 9\% (8/88), p=0.03. Adjustment for these variables, however, did not affect any comparison between the treatment groups.

The spirometry and exhaled nitric oxide $\left(\mathrm{FE}_{\mathrm{NO}}\right)$ levels were similar in the two treatment groups (Table 2). The FE $\mathrm{NO}_{\mathrm{NO}}$ levels were also similar between children with and without asthma (data not shown), although pathological levels (>20 ppb) were more common in children with asthma, $24 \%$ (5/21) vs. $2 \%(2 / 117), \mathrm{p}=0.001$. There were no differences in growth indices (Table 3), nor in the prevalence of gastrointestinal symptoms between the treatment groups (Table 1). No severe adverse events were reported. 



\section{Discussion}

The effect of Lactobacillus reuteri on sensitisation and IgE-associated eczema in infancy (13) did not lead to a lower prevalence of respiratory allergic disease in school age. The lack of effect on these manifestation is consistent with previous follow ups with other probiotic strains $(5,6,20)$. The difference in sensitisation between the probiotic and placebo group at two years (13) was also gone at seven years of age. Thus, the effect of L reuteri on the immune system seems to be transient. Since the number of children delivered with ceasarean section was low, the effect of probiotics in this subgroup in a previous follow up study (6) could not be properly evaluated.

Our results are consistent with the findings that L. reuteri colonisation at birth only decreased Th2- and increased Th1-associated chemokines at six months of age and not later (14). Why the effect was transient is unclear. As only infants with confirmed L. reuteri colonisation and not all those who were treated with $L$. reuteri had a low Th2/Th1 chemokine ratio (14), the dose $\left(10^{8}\right.$ bacteria/day) might have been too low for a permanent immunological effect. The colonisation of $L$. reuteri was also transient (15), with no persistent effect on the gut microbiota (2). Furthermore, the action of $L$. reuteri that resulted in less sensitisation in infancy and the mechanisms underlying eczema and asthma in school age may be separate phenomena. We have observed immunomodulatory effects on allergen-induced cytokine responses in probiotic treated infants that were not related to atopic disease development, indicating independent effects (21). An alternative explanation for the absent effect on sensitisation at seven years could be a false positive result in the two-year follow, despite the double-blind randomised-controlled design (13). The effect on atopy remained after adjustments for possible confounders, however, reducing the risk of a false positive result (13). The lack of blinding of the participants and assessors could theoretically have affected 
the result at seven years of age as well.

If prenatal microbial exposure is vital for a sustained preventive effect, as suggested by epidemiological $(22,23)$ and experimental $(24,25)$ studies, then probiotic supplementation should possibly be prolonged and started already from the second trimester of pregnancy, when circulating fetal T cells have developed (26, 27). Prenatal environmental exposures may alter gene expression via epigenetic mechanisms, inducing physiological adaptations to the anticipated postnatal environment (28). Moreover, recent studies indicate a stronger protective effect on the child, if the mother are supplemented with probiotics both pre- and postnatally (29, 30), possibly because decrease mismatched responses $(26,27)$.

In parallel with the lack of effect on the immune system, there were no signs of any long-term side effects in this follow up until school age. Thus, there were no indications of higher prevalence of allergic disease, no reports of severe side effects, and growth indices were similar in the probiotic and placebo groups. This is an important notion, since there have been concerns about treatment of vulnerable newborns and that the follow up period has been too short, often only until two years of age (3).

In conclusion, the effect of $L$. reuteri on sensitisation and IgE-associated eczema in infancy did not lead to a lower prevalence of respiratory allergic disease in school age. The effect of L. reuteri on the immune system seems to be transient. Administration of Lactobacillus reuteri perinatally was not associated with any long-term side effects until school age. 


\section{Acknowledgements}

We thank Mrs Lena Lindell, Mrs Elisabeth Andersson, Mrs Linnea Andersson and Mrs Eivor

Folkesson for their enthusiastic work guiding the families through the study, and Mrs AnneMarie Fornander for excellent technical assistance.

\section{Disclosure}

T Abrahamsson, M Jenmalm and B Björkstén have received honoraria for lectures from Biogaia AB 


\section{References}

1. Wold A. The hygiene hypothesis revised: is the rising frequency of allergy due to changes in the intestinal flora? Allergy 1998; 53 suppl: 20-5.

2. Abrahamsson TR, Jakobsson HE, Andersson AF, Björkstén B, Engstrand L, Jenmalm MC. Low diversity of the gut microbiota in infants with atopic eczema. J Allergy Clin Immunolol 2012; 129: 434-40.

3. Ismail IH, Licciardi PV, Tang ML. Probiotic effects in allergic disease. $J$ Paediatr Child Health 2013.

4. Wood RA. The natural history of food allergy. Pediatrics 2003; 111: 1631-7. 5. Kalliomäki M, Salminen SJ, Poussa T, Isolauri E. Probiotics during the first 7 years of life: a cumulative risk reduction of eczema in a randomized, placebo-controlled trial. . J Allergy Clin Immunolol 2007; 119: 1019-21.

6. Kuitunen M, Kukkonen K, Juntunen-Backman K, et al. Probiotics prevent IgEassociated allergy until age 5 years in cesarean-delivered children but not in the total cohort. $J$ Allergy Clin Immunolol 2009; 123: 335-41.

$7 . \quad$ Kalliomäki M, Salminen SJ, Arvilommi H, Kero P, Koskinen P, Isolauri E. Probiotics in primary prevention of atopic disease: a randomised placebo-controlled trial. Lancet 2001; 357: 1076-79.

8. Wickens K, Black PN, Stanley TV, et al. A differential effect of 2 probiotics in the prevention of eczema and atopy: a double-blind, randomized, placebo-controlled trial. $J$ Allergy Clin Immunol 2008; 122: 788-94.

9. Wickens K, Black P, Stanley TV, et al. A protective effect of Lactobacillus rhamnosus HN001 against eczema in the first 2 years of life persists to age 4 years. Clin Exp Allergy 2012; 42: 1071-9.

10. Kukkonen K, Savilahti E, Haahtela T, et al. Probiotics an prebiotic galactoligasaccharides in prevention of allergic diseases: a randomized double-blind placebocontrolled trial. J Allergy Clin Immunolol 2007; 119: 192-98.

11. Campana R, Mothes N, Rauter I, et al. Non-IgE-mediated chronic allergic skin inflammation revealed with rBet v 1 fragments. J Allergy Clin Immunol 2008; 121: 528-30 12. Novembre E, Cianferoni A, Lombardi E, Bernardini R, Pucci N, Vierucci A. Natural history of "intrinsic" atopic dermatitis. Allergy 2001; 56: 452-53.

13. Abrahamsson TR, Jakobsson T, Böttcher MF, et al. Probiotics in prevention of IgE-associated eczema: a double blind randomised placebo-controlled trial. J Allergy Clin Immunolol 2007; 119: 1174-80.

14. Abrahamsson TR, Sandberg Abelius M, Forsberg A, Björkstén B, Jenmalm MC. A Th1/Th2-associated chemokine imbalance during infancy in children developing eczema, wheeze and sensitization. Clin Exp Allergy 2011; 41: 1729-39.

15. Abrahamsson TR, Sinkiewicz G, Jakobsson T, Fredrikson M, Björkstén B. Probiotic lactobacilli in breast milk and infant stool in relation to oral intake during the first year of life. J Pediatr Gastroenterol Nutr 2009; 49: 349-54.

16. Severity Scoring of Atopic Dermatitis: The SCORAD index. Consensus report from the of the European Task Force on atopic dermatitis. Dermatology 1993; 186: 23-31.

17. Buchvald F, Baraldi E, Carraro S, et al. Measurements of exhaled nitric oxide in healthy subjects age 4 to 17 years. J Allergy Clin Immunolol 2005; 115: 1130-6.

18. Asher MI, Keil U, Anderson HR, et al. International Study of Asthma and Allergies in Childhood (ISAAC): rationale and methods. Eur Respir J 1995; 8: 483-91. 19. Hanifin JM, Rajka G. Diagnostic features of atopic dermatitis. Acta Dermatol Venereol 1980; (Suppl 92): 44-7. 
20. Jensen MP, Meldrum S, Taylor AL, Dunstan JA, Prescott SL. Early probiotic supplementation for allergy prevention: Long-term outcomes. J Allergy Clin Immunolol 2012; 130: $1209-11$ e5.

21. Forsberg A, Abrahamsson TR, Björksten B, Jenmalm MC. Pre- and post-natal Lactobacillus reuteri supplementation decreases allergen responsiveness in infancy. Clin Exp Allergy 2013; 43: 434-42.

22. Ege MJ, Bieli C, Frei R, et al. Prenatal farm exposure is related to the expression of receptors of the innate immunity and to atopic sensitization in school-age children. $J$ Allergy Clin Immunol 2006; 117: 817-23.

23. Douwes J, Cheng S, Travier N, et al. Farm exposure in utero may protect against asthma, hay fever and eczema. Eur Respir J 2008; 32: 603-11.

24. Conrad ML, Ferstl R, Teich R, et al. Maternal TLR signaling is required for prenatal asthma protection by the nonpathogenic microbe Acinetobacter lwoffii F78. $J$ Exp Med 2009; 206: 2869-77.

25. Cao L, Wang J, Zhu Y, Tseu I, Post M. Maternal endotoxin exposure attenuates allergic airway disease in infant rats. Am J Physiol Lung Cell Mol Physiol 2010; 298: L670-7. 26. Jenmalm MC, Duchen K. Timing of allergy preventive and immunomodulatory dietary interventions are prenatal, perinatal or postnatal strategies optimal? . Clin Exp Allergy 2013; 43: 273-8.

27. Jenmalm MC. Childhood immune maturation and allergy development: regulation by maternal immunity and microbial exposure. Am J Reprod Immunol 2011; 66 Suppl 1: 75-80.

28. Wadhwa PD, Buss C, Entringer S, Swanson JM. Developmental origins of health and disease: brief history of the approach and current focus on epigenetic mechanisms. Semin Reprod Med 2009; 27: 358-68.

29. Rautava S, Kainonen E, Salminen S, Isolauri E. Maternal probiotic supplementation during pregnancy and breast-feeding reduces the risk of eczema in the infant. J Allergy Clin Immunolol 2012.

30. Boyle RJ, Ismail IH, Kivivuori S, et al. Lactobacillus GG treatment during pregnancy for the prevention of eczema: a randomized controlled trial. Allergy 2011; 66: 50916. 


\section{Tables}

Table 1. The background factors and gastrointestinal symptoms in children supplemented with $L$. reuteri or placebo during the first year of life and that completed the 7-years follow up

Family size at 7 y mean (ci)

Boys

Older sibling

Maternal atopy

Asthma in family

Parental smoking (prebirth)

Parental smoking at $7 \mathrm{y}$

Furred pets at 7 y

Caesarean section

Breastfeeding excl. at $3 \mathrm{~m}$

Breastfeeding at $6 \mathrm{~m}$

Day-care at 24 months of age

Antibiotics 0-12m

Antibiotics last month

Probiotics last month

Irritated bowel syndrom (IBS)** stool $>3$ times per day stool $<3$ times per week

Gastroenteritis last month

Celiac disease

\begin{tabular}{|c|c|c|}
\hline L. reuteri & placebo & $\mathrm{P}^{*}$ \\
\hline $4.4(4.2-4.6)$ & $4.4(4.2-4.6)$ & $\overline{0.66}$ \\
\hline $55(52 / 94)$ & $48(44 / 90)$ & 0.38 \\
\hline $51(48 / 94)$ & $42(38 / 90)$ & 0.23 \\
\hline $75(70 / 94)$ & $78(70 / 90)$ & 0.60 \\
\hline $49(46 / 94)$ & $46(41 / 90)$ & 0.65 \\
\hline $7(7 / 94)$ & $12(11 / 90)$ & 0.28 \\
\hline $3(3 / 94)$ & $10(9 / 90)$ & 0.06 \\
\hline $27(25 / 93)$ & $29(26 / 90)$ & 0.64 \\
\hline $11(10 / 94)$ & $15(13 / 90)$ & 0.44 \\
\hline $70(66 / 94)$ & $79(71 / 90)$ & 0.18 \\
\hline $84(79 / 94)$ & $84(76 / 90)$ & 0.94 \\
\hline $81(76 / 94)$ & $84(76 / 90)$ & 0.52 \\
\hline $36(34 / 94)$ & $20(18 / 90)$ & 0.03 \\
\hline $5(5 / 94)$ & $3(3 / 90)$ & 0.72 \\
\hline $19(18 / 94)$ & $26(23 / 90)$ & 0.30 \\
\hline $18(17 / 94)$ & $14(12 / 90)$ & 0.38 \\
\hline $4(4 / 94)$ & $5(4 / 90)$ & 0.95 \\
\hline $14(13 / 94)$ & $9(8 / 90)$ & 0.29 \\
\hline $14(13 / 94)$ & $8(7 / 90)$ & 0.19 \\
\hline $1(1 / 94)$ & $1(1 / 90)$ & 1.00 \\
\hline
\end{tabular}

* Chi2 test was employed for cathegorical variable. Fisher's exact test was used when the expected frequency for any cell was less than five. Student t-test was employed for continuous variables. ${ }^{* *}$ IBS $=$ stool $>3$ times per day or $<3$ times per week last 6 months. 
Table 2. The prevalence of allergic disease between six and seven years of age and positive skin prick test and spirometry and fractional exhaled NO values at seven years of age in children supplemented with $L$. reuteri or placebo during the first year of life

\begin{tabular}{|c|c|c|c|}
\hline & $\begin{array}{l}\text { L reuteri } \\
\%(n / N)\end{array}$ & $\begin{array}{l}\text { placebo } \\
\%(n / N)\end{array}$ & P-value* \\
\hline Wheeze at $7 y$ & $19(18 / 94)$ & $16(14 / 90)$ & 0.52 \\
\hline Asthma at $7 y$ & $15(14 / 94)$ & $16(14 / 90)$ & 0.88 \\
\hline Asthma at $2 y$ and/or $7 y$ & $18(17 / 94)$ & $17(15 / 90)$ & 0.80 \\
\hline Asthma (pos test at visit) $7 \mathbf{y}^{* *}$ & $9(5 / 57)$ & $6(4 / 63)$ & 0.73 \\
\hline Allergic rhinoconjunct. at $7 y$ & $27(25 / 94)$ & $20(18 / 90)$ & 0.29 \\
\hline$A R C$ at $2 y$ and/or $7 y$ & $27(25 / 94)$ & $22(19 / 90)$ & 0.38 \\
\hline Respiratory allergy at $7 y$ & $35(33 / 94)$ & $29(26 / 90)$ & 0.37 \\
\hline Allergic urticaria at $7 y$ & $5(5 / 94)$ & $2(2 / 90)$ & 0.45 \\
\hline Eczema at $7 y$ & $21(20 / 94)$ & $19(17 / 90)$ & 0.69 \\
\hline Eczema at $2 y$ and/or $7 y$ & $42(39 / 94)$ & $40(36 / 90)$ & 0.84 \\
\hline Allergic disease at $7 y$ & $42(39 / 94)$ & $42(37 / 90)$ & 0.96 \\
\hline Allergic dis. at 2 and/or $7 y$ & $60(56 / 94)$ & $57(51 / 90)$ & 0.69 \\
\hline Skin prick test pos at $7 y$ & $29(23 / 80)$ & $26(20 / 77)$ & 0.70 \\
\hline SPT pos at 2 and/or $7 y$ & $35(29 / 82)$ & $45(37 / 82)$ & 0.20 \\
\hline $\begin{array}{l}\text { IgE-associated eczema at } \mathbf{7 y} \\
\text { (SPT pos+eczema) }\end{array}$ & $16(13 / 80)$ & $14(11 / 77)$ & 0.73 \\
\hline \multirow{2}{*}{$\begin{array}{l}\text { IgE-as. ecz. at } 2 \mathbf{y} \text { and/or } 7 \mathbf{y} \\
\text { (SPT pos+eczema) }\end{array}$} & $25(20 / 81)$ & $27(22 / 81)$ & 0.72 \\
\hline & median (iq) & median (iq) & \\
\hline $\begin{array}{l}\text { SCORAD at } 7 \mathbf{y} \\
\text { (in children with eczema) }\end{array}$ & $7(0-11) n=17$ & $11(5-18) n=17$ & 0.053 \\
\hline $\mathbf{F E}_{\text {NO }}(\mathrm{ppb})$ & $9.3(6.9-12.0) n=70$ & $11.0(7.0-11.0) n=68$ & 0.55 \\
\hline $\mathbf{F E}_{\text {NO }} \geq \mathbf{2 0} \mathbf{p p b}$ (pathological) & $4(3 / 70)$ & $6(4 / 68)$ & 0.72 \\
\hline & $1.55(1.43-1.64)$ & $1.44(1.32-1.65)$ & \\
\hline $\mathbf{F E V}_{1}(\mathrm{~L})$ & $\mathrm{n}=57$ & $\mathrm{n}=63$ & 0.09 \\
\hline $\mathrm{FEV}_{1} \%\left(\mathrm{FEV}_{1} / \mathrm{FVC}\right)$ & $87(83.5-95) n=57$ & $88.5(84.4-96) n=63$ & 0.45 \\
\hline $\mathbf{F E V}_{\mathbf{1}} \%<\mathbf{8 0 \%}$ (pathological) & $9(5 / 57)$ & $5(3 / 63)$ & 0.48 \\
\hline FEV $_{1}$-reversibility $>12 \%$ & $12(7 / 57)$ & $8(5 / 63)$ & 0.43 \\
\hline
\end{tabular}

* Chi2 test was employed for cathegorical variable. Fisher's exact test was used when the expected frequency for any cell was less than five. Mann-Whitney $U$ test was employed for continuous varbiables

** Children with asthma that had a positive $\mathrm{FEV}_{1}$-reversibility test and/or pathological $\mathrm{FE}_{\mathrm{NO}}$ value at the visit. Only children with correct spirometry technique $(\mathrm{n}=120)$ were included in this analysis 
Table 3. Weight and length (mean and 95\% confidence interval) from birth until seven years of age in children supplemented with $L$. reuteri or placebo during the first year of life.

\begin{tabular}{|c|c|c|c|c|c|c|c|c|}
\hline & \multicolumn{4}{|c|}{ Weight (kg) } & \multicolumn{4}{|c|}{ Height (cm) } \\
\hline & L. reuteri & (n) & Placebo & $(n)$ & L. reuteri & (n) & Placebo & (n) \\
\hline Birth & $3.66(3.56-3.75)$ & (95) & $3.60(3.50-3.71)$ & (93) & $51.3(50.9-51.7)$ & (95) & $50.8(50.4-51.2)$ & (93) \\
\hline z score* & $0.08(-0.12-0.28)$ & & $-0.02(-0.24-0.21)$ & & $0.03(-0.23-0.28)$ & & $-0.22(-0.49-(-0.05))$ & \\
\hline 3 months & 6.35 (6.19-6.51)\# & (95) & 6.10 (5.95-6.25)\# & (93) & $61.9(61.5-62.4)$ & (95) & $61.4(61.0-61.9)$ & (93) \\
\hline z score* & $0.43(0.21-0.65)$ & & $0.12(-0.10-0.34)$ & & $0.84(0.61-1.07)$ & & $0.61(0.39-0.83)$ & \\
\hline 6 months & $8.13(7.92-8.34)$ & (95) & 7.88 (7.69-8.07) & (93) & $68.1(67.7-68.5)$ & (95) & $67.6(67.2-68.2)$ & (93) \\
\hline z score* & $0.34(0.10-0.58)$ & & $0.13(-0.09-0.34)$ & & $0.51(0.29-0.73)$ & & $0.34(0.12-0.56)$ & \\
\hline 1 year & $10.23(10.0-10.4)$ & (95) & $10.07(9.9-10.3)$ & (93) & 76.4 (76.0-76.9) & (95) & $76.0(75.5-76.5)$ & (93) \\
\hline z score* & $0.15(-0.14-0.44)$ & & $-0.02(-0.21-0.16)$ & & $0.44(0.26-0.62)$ & & $0.25(0.05-0.44)$ & \\
\hline 2 years & $13.1(12.8-13.4)$ & (94) & $13.0(12.7-13.3)$ & $(92)$ & $88.1(87.5-88.7)$ & (94) & $87.5(86.9-88.0)$ & $(90)$ \\
\hline z score* & $-0.06(-0.28-0.16)$ & & $-0.04(-0.27-0.18)$ & & $0.17(-0.2-0.36)$ & & $-0.03(-0.21-0.15)$ & \\
\hline 7 years & $25.4(24.6-26.3)$ & $(81)$ & $25.5(24.5-26.6)$ & $(77)$ & $124.7(123.6-125.8)$ & (81) & $124.2(123-125.5)$ & (77) \\
\hline z score** & $0.28(0.09-0.46)$ & & $0.32(0.11-0.52)$ & & $0.09(-0.10-0.29)$ & & $-0.01(-0.19-0.21)$ & \\
\hline
\end{tabular}

Student t-test: \#p=0.02. Z score in relation to growth curves by * Niklasson 2008 and **Albertsson-Wikland 2002. 
Supplementary Table 1. The predictive value of various allergic manifestation at two years of age for allergic diseases at seven years of age in all children.

\begin{tabular}{|c|c|c|c|c|c|c|c|c|c|c|c|}
\hline \multirow{2}{*}{$\begin{array}{l}\text { Manifestation at } \\
2 \text { years: }\end{array}$} & & \multicolumn{2}{|l|}{ Asthma at $7 \mathbf{y}$} & \multicolumn{2}{|l|}{ ARC at $7 y$} & \multicolumn{2}{|l|}{ Eczema at $7 y$} & \multicolumn{2}{|l|}{ SPT at $7 y$} & \multicolumn{2}{|c|}{ Any disease at $7 y$} \\
\hline & & $\%(\mathrm{n} / \mathrm{N})$ & $\mathrm{p}^{*}$ & $\%(\mathrm{n} / \mathrm{N})$ & $\mathrm{p}^{*}$ & $\%(\mathrm{n} / \mathrm{N})$ & $\mathrm{p}^{*}$ & $\%(\mathrm{n} / \mathrm{N})$ & $\mathrm{p}^{*}$ & $\%(\mathrm{n} / \mathrm{N})$ & $\mathrm{p}^{*}$ \\
\hline Eczema & $\begin{array}{l}\text { PPV } \\
\text { NPV }\end{array}$ & $\begin{array}{l}23(15 / 64) \\
89(107 / 120)\end{array}$ & 0.02 & $\begin{array}{l}39(25 / 64) \\
85(102 / 120)\end{array}$ & $<0.001$ & $\begin{array}{l}41(26 / 64) \\
91(109 / 120)\end{array}$ & $<0.001$ & $\begin{array}{l}46(25 / 54) \\
83(85 / 103)\end{array}$ & $<0.001$ & $\begin{array}{l}67(43 / 64) \\
73(87 / 120)\end{array}$ & $<0.001$ \\
\hline $\begin{array}{l}\text { IgE-associated } \\
\text { eczema }\end{array}$ & $\begin{array}{l}\text { PPV } \\
\text { NPV }\end{array}$ & $\begin{array}{l}33(11 / 33) \\
87(101 / 116)\end{array}$ & 0.006 & $\begin{array}{l}39(13 / 33) \\
80(93 / 116)\end{array}$ & 0.02 & $\begin{array}{l}46(15 / 33) \\
85(99 / 116)\end{array}$ & $<0.001$ & $\begin{array}{l}57(16 / 28) \\
80(81 / 101)\end{array}$ & $<0.001$ & $\begin{array}{l}79(26 / 33) \\
68(79 / 116)\end{array}$ & $<0.001$ \\
\hline Sensitization & $\begin{array}{l}\text { PPV } \\
\text { NPV } \\
\end{array}$ & $\begin{array}{l}29(18 / 63) \\
91(78 / 86) \\
\end{array}$ & 0.002 & $\begin{array}{l}37(23 / 63) \\
85(73 / 86) \\
\end{array}$ & 0.003 & $\begin{array}{l}29(18 / 63) \\
84(72 / 86) \\
\end{array}$ & 0.07 & $\begin{array}{l}50(27 / 54) \\
88(66 / 75) \\
\end{array}$ & $<0.001$ & $\begin{array}{l}64(40 / 63) \\
73(63 / 83) \\
\end{array}$ & $<0.001$ \\
\hline
\end{tabular}

*Chi2 test was employed to analyse whether the allergic manifestation at two years of age was significantly associated with the allergic disease at seven years of age. ${ }^{* *}$ Compared with infants without eczema and/or sensitisation. PPV=positive predictive value, NPV= negative predictive value 